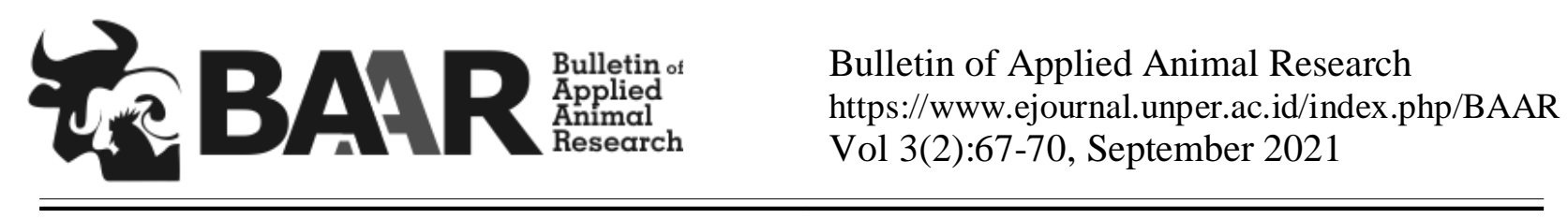

\title{
Pemanfaatan Kotoran Kambing Sebagai Bahan Bakar Renewable (Gas Bio) Untuk Menghindari Pencemaran Lingkungan Di Desa Binangun Kecamatan Banyumas Kabupaten Banyumas
}

\author{
${ }^{1}$ S.A.C. Luthfi, ${ }^{2}$ R. Fitria, ${ }^{3}$ N.Hindratiningrum \\ ${ }^{1,2,3}$ Program Studi Peternakan Fakultas Sains dan Teknologi \\ Universitas Nahdlatul Ulama Purwokerto \\ Jalan Sultan Agung no 42 Karangklesem Purwokerto Selatan, Jawa Tengah 53145 \\ *Corresponding E-mail : sacluthfi@gmail.com
}

\begin{abstract}
ABSTRAK
Masalah yang dihadapi kelompok Tani Ternak "Sida Maju 1" dan "Tangkas di Desa Binangun adalah adalah penanganan limbah yang belum tertangani dengan baik karena limbah yang dihasilkan dari proses pemeliharaan hanya ditumpuk dan tentu saja menyebabkan pencemaran lingkungan. Tujuan kegiatan ini adalah memanfaatkan limbah usaha peternakan kambing milik anggota kelompok tersebut menjadi sumber renewable energy berupa biogas. Metode yang digunakan adalah metode consulting yang diawali dengan pendekatan, kemudian diberikan penyuluhan, pelatihan dan pembinaan serta terakhir adanya evaluasi dan monitoring berkelanjutan dari pihak pelaksana program. Hasil kegiatan ini adalah (1) meningkatnya pengetahuan, sikap dan ketrampilan peternak dalam hal memanfaatkan kotoran kambing menjadi gas bio yang dapat dilihat dari penigkatan nilai post test dibandingkan pretest sebesar $81 \%$; (2) biogas yang dihasilkan dapat menghidupkan kompor selama 7 menit. Kesimpulan kegiatan ini adalah meningkatnya kemampuan peternak dalam memanfaatkan limbah menjadi bahan yang berguna. Saran yang dapat disampaikan adalah perlu penambahan populasi ternak kambing yang dimiliki anggota agar volume gas yang dihasilkan lebih besar sehingga pemanfaatannya lebih optimal.
\end{abstract}

Kata kunci : kotoran kambing, gas bio

\begin{abstract}
The problem faced by the "Sida Maju 1" and "Tangkas Farmers" in Binangun Village is the handling of waste that is not handled properly because the maintenance process is only piled up and of course causes environmental pollution. The purpose of this activity is to utilize the business waste belonging to the group members into a renewable energy source in the form of biogas. The method used is a consultation method that begins with an approach, then is given counseling, training and coaching and finally continuous evaluation and monitoring from the program implementer. The results of this activity are (1) knowledge, attitudes and skills to become livestock in terms of utilizing bio gas waste, which can be seen from the increase in the post test score compared to the pretest by $81 \%$; (2) the biogas produced can light the stove for 7 minutes. The conclusion of this activity is the skills of farmers in utilizing waste into useful materials. Suggestions that can be submitted is to increase the population of goats owned by members so that the volume of gas produced is greater so that its utilization is more optimal.
\end{abstract}

Keywords: goat manure, bio gas 


\section{INTRODUCTION}

Kabupaten Banyumas merupakan salah satu daerah dengan jumlah ternak kambing cukup tinggi yaitu 165.276 ekor pada tahun 2018 (BPS Banyumas, 2019). Peternak kambing di daerah Kabupaten Banyumas sudah banyak yang tergabung dalam Kelompok Tani Ternak (KTT), diantaranya di Desa Binangun. Kelompok yang terdapat di Desa Binangun diantaranya adalah KTT Sida Maju 1 di RT 01 RW 04 (dengan ketua Bapak Bambang Edi Sunarto) dan KTT Kelompok Tangkas di RT 04 RW 03 (diketuai oleh Bapak Amaludin). Jumlah anggota kedua kelompok sebanyak 25 orang dengan pemilikan ternak rata-rata sebanyak 4 ekor. Kedua KTT Desa Binangun tersebut sudah dapat digolongkan maju karena pemeliharaan ternaknya dilakukan dalam kandang komunal. Kendala yang dihadapi oleh peternak di KTT Sida Maju 1 dan Kelompok tangkas adalah penanganan limbah. Limbah yang dihasilkan dari proses pemeliharaan hanya ditumpuk saja sambil menunggu pembeli. Kondisi tersebut pada akhirnya akan mencemari lingkungan. Limbah peternakan pada peternakan kambing merupakan salah satu jenis bahan baku yang dapat digunakan pada teknologi pembentukan biogas. Biogas merupakan salah satu sumber energi terbarukan yang dapat menjawab kebutuhan energi alternatif. Biogas adalah gas yang dihasilkan dari proses penguraian bahan-bahan organik oleh mikroorganisme dalam keadaan anaerob (Wahyuni, 2015). Biogas yang dihasilkan dapat digunakan untuk memasak, penerangan, dan bahan bakar motor atau genset (Haryanto, 2014).

Biogas mempunyai beberapa keunggulan dibandingkan dengan BBM yang berasal dari fosil. Sifatnya yang ramah lingkungan dan dapat diperbaharui merupakan keunggulan dari biogas dibandingkan dengan bahan bakar fosil (Wahyuni, 2015). Biogas merupakan sumber renewable energy yang mampu memberikan andil dalam usaha memenuhi kebutuhan bahan bakar. Bahan baku sumber energi biogas merupakan bahan non-fosil, umumnya adalah biomass yang mengandung bahan organik yang tersedia sangat melimpah di Indonesia, diantaranya adalah sumber daya peternakan dan pertanian. Biogas merupakan salah satu dari banyak macam sumber energi terbarukan, karena energi biogas dapat diperoleh dari buangan rumah tangga, kotoran cair dari peternakan ayam, sapi, kambing, babi, sampah organik dari pasar, industri makanan dan limbah buangan lainnya. Jenis kotoran ternak mempengaruhi biogas yang dihasilkan, hal ini terkait dengan hubungan antara jumlah karbon dan nitrogen yang dinyatakan dengan rasio karbon nitrogen $(\mathrm{C} / \mathrm{N})$, rasio optimum untuk digester anaerobik berkisar 25 - 30 (Wahyuni, 2011). Kotoran kambing sebanyak 12 liter menurut Putri, et al., (2014) mampu menghasilkan biogas rata-rata sebesar 1,083 liter. Rahmat, et al. (2018) menyatakan bahwa satu ekor kambing mampu menghasilkan feses/kotoran sebanyak $1,13 \mathrm{~kg}$ per hari yang mampu menghasilkan biogas sebesar 0,040 $0,059 \mathrm{~m} 3 / \mathrm{kg}$. BK dimana hal tersebut menunjukkan biogas yang dihasilkan dari $1 \mathrm{~kg}$ kotoran kambing.

Tujuan kegiatan Pengabdian kepada masyarakat ini adalah memanfaatkan limbah usaha peternakan kambing milik anggota kelompok Tani Ternak di Desa Binangun berupa kotoran ternak menjadi sumber renewable energy berupa biogas. Manfaat yang diperoleh adalah : (1) memberikan pengetahuan dan wawasan bagi masyarakat khususnya peternak tentang teknologi biogas dalam memanfaatkan kotoran kambing; (2) Memberikan ghasilkan biogas dan merawat instalasinya agar dapat dimanfaatkan.

\section{MATERIALS AND METHODS}

Metode yang akan dilaksanakan dalam kegiatan di KTT "Sida Maju 1" dan "Tangkas" Desa Binangun Kecamatan Banyumas Kabupaten Banyumas adalah metode Consulting. Metode ini diawali dengan pendekatan, kemudian diberikan penyuluhan, pelatihan dan pembinaan serta terakhir adanya evaluasi dan monitoring berkelanjutan dari pihak pelaksana program. Penyuluhan yang dilaksanakan telah mampu menciptakan inovasi baru yang dapat diterapkan serta disosialisasikan di masyarakat. Materi-materi yang berkaitan akan diberikan sebelum pelatihan dilakukan. Pelatihan yang akan 
diberikan meliputi pelatihan teknologi pengolahan limbah peternakan menjadi biogas. Materi yang diberikan meliputi : manfaat limbah peternakan sebagai bahan baku pembuatan biogas, cara pembuatan biogas, macam-macam digester, reactor biogas, dan proses produksi biogas. Teknis penerapan teknologi dengan memberikan bantuan instalasi penghasil biogas. Digester yang digunakan dalam teknologi gas bio ini adalah digester plastik.
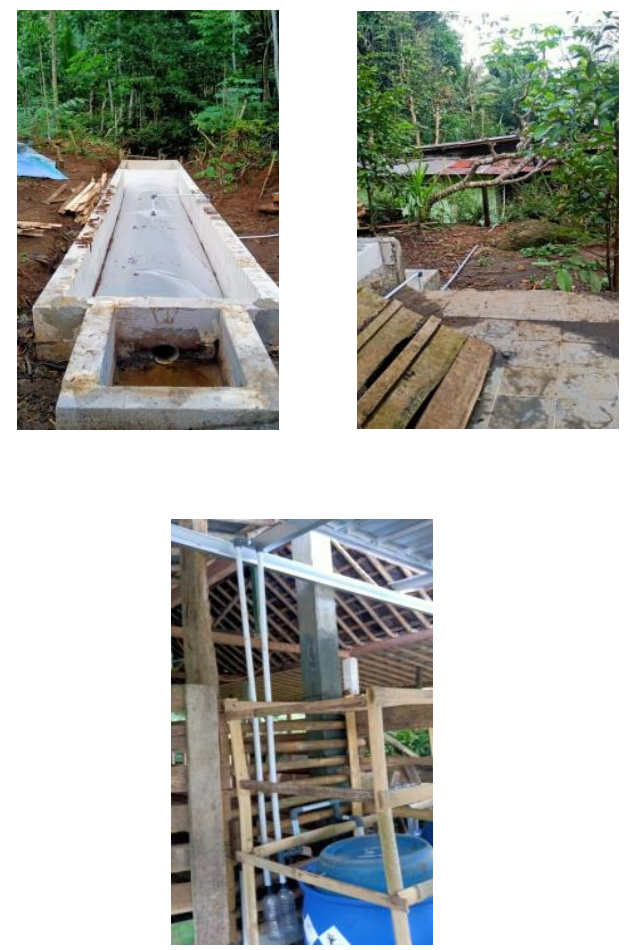

Gambar 1. Digester plastik, penampung biogas dan penyaluran gas ke rumah peternak

Proses Pembuatan digester plastik adalah sebagai berikut : (1) Buat galian tanah ukuran lebar 1 meter, dalam 1 meter panjang 5 meter, (2) Pasang herbel di dalam galian yang sudah dibuat (3) Pasang paralon 4" di inlet dan outlet (4) Pasang plastik untuk digester (5) Pasang instalasi (6) Masukan kotoran Minimal10 karung yang sudah di hancurkan campur dengan air $1: 2$ pada bak penampungan sementara / bak pencampur. (7) Masukkan lumpur kotoran tersebut ke dalam biodigester melalui lubang pemasukan (inlet) (8) Mulai hari ke 21 dan seterusnya sudah terbentuk gas methana (CH4) yang dapat digunakan sebagai bahan bakar untuk menyalakan kompor gas. (9) Setiap hari, digester harus selalu diisi lumpur kotoran kambing untuk menghasilkan biogas yang optimal.

Setelah mendapatkan penyuluhan dan pelatihan, peternak akan dibimbing dan dibina agar usaha peternakan kambing mereka yang menerapkan teknologi pengolahan limbah peternakan untuk pembangunan biogas, penerapan kalender reproduksi dan pembenahan administrasi kelompok.

Monitoring akan dilakukan oleh tim pelaksana dan berkala ( $2-3$ minggu sekali). Diskusi dan konsultasi dilakukan saat monitoring untuk mencari solusi dari berbagai kendala yang dihadapi dalam hal pemanfaatan kotoran menjadi biogas, penerapan kalender reproduksi dan pembenahan administrasi kelompok.

\section{RESULTS AND DISCUSSION}

Hasil kegiatan pengabdian kepada masyarakat ini secara keseluruhan dapat diterima oleh Kelompok Tani Ternak di Desa Binangun Kecamatan Banyumas Kabupaten Banyumas. Dampak kegiatan dapat dibagi dalam 2 (dua) hal yaitu dampak ekonomi dan dampak sosial. Dampak ekonomi dapat dikatakan anggota kelompok yang menjadi sampel pengaliran gas bio merasa diuntungkan. Anggota tersebut menyatakan bahwa dia bisa memanfaatkan gas bio yang dihasilkan untuk merebus air sebanyak 2 liter per hari. Hal ini karena memang hasil gas bio belum banyak karena jumlah ternak yang dipelihara juga masih sekitar 20 ekor. Selain itu, dampak ekonomi yang juga dirasakan oleh peternak adalah penghasilan tambahan dari penjualan pupuk padat organik yang merupakan hasil dari pengolahan ampas kotoran sisa pembuatan gas bio.

Dampak sosial lebih nampak, terutama terkait masalah pencemaran lingkungan. Kotoran kambing berikut sisa pakannya seluruhnya dimasukkan ke dalam digester sehingga mengurangi bau yang timbul. Peternak juga mendapatkan peningkatan pengetahuan dan ketrampilan tentang gas bio dan perawatan serta pengelolaannya. Berdasarkan kegiatan monitoring dan evaluasi tim pelaksana, anggota kelompok tidak mengalami kendala yang berarti dalam 
menghasilkan gas bio, merawat instalasi dan pengelolaannya. Kendala yang cukup berarti adalah waktu pelaksanaan kegiatan yang sangat pendek sehingga dampak yang lebih baik belum dapat diamati.
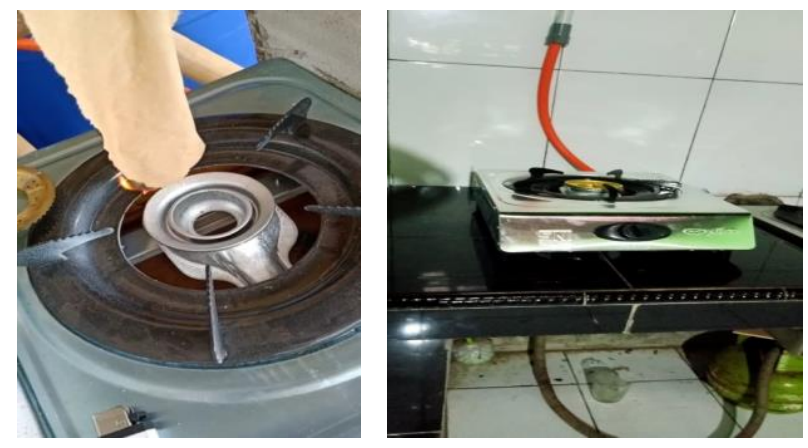

Gambar 2. Pemanfaatan gas bio yang dihasilkan dari kotoran kambing

Faktor pendorong kegiatan program pengabdian kepada masyarakat ini adalah semangat dan antusiasme serta kerjasama yang terbina dengan baik. Anggota kelompok seluruhnya mengikuti tahapan yang dilaksanakan oleh tim pelaksana sehingga setiap kendala yang dihadapi selalu didiskusikan bersama untuk memperoleh solusi terbaik.

\section{KESIMPULAN}

Berdasarkan hasil kegiatan program pengabdian kepada masyarakat yang dilaksanakan diperoleh kesimpulan:

1.Kegiatan pemanfaatan limbah kotoran kambing menjadi gas bio dapat mengurangi pencemaran lingkungan sekitar kandang sehingga tercipta lingkungan yang lebih bersih

2.Gas bio yang dihasilkan dapat membantu peternak menghemat pengeluaran dan mengurangi penggunaan bahan bakar asal fosil.

\section{REFERENSI}

Badan Pusat Statistik, 2019. Kecamatan Banyumas dalam Angka. Badan Pusat Statistik Kabupaten Banyumas. Publikasi online.

Haryanto, A. 2014. Energi Terbarukan. Bandar Lampung. Bab V : 195 - 246.

Putri, A.A.I.K., I Wayan Suarta Asmara, I Ketut Aryana. 2014. Pengaruh Jenis Kotoran Ternak Terhadap Kantitas Biogas. Jurnal Kesehatan Lingkungan. Vol 4. No. 1. Mei.

Wahyuni, S. 2011. Menghasilkan Biogas dari aneka limbah. Agro Media Pustaka. Jakarta

Wahyuni, S. 2013. Biogas Energi Alternatif Pengganti BBM, Gas, dan Listrik. PT. Agro Media Pustaka. Jakarta Selatan. 117 hlm.

Wahyuni, S. 2015. Panduan Praktis Biogas. Penebar Swadaya. Jakarta Timur. 116 hlm.. 